\title{
Ablation for atrial fibrillation: CT overlay or standard electroanatomical mapping?
}

\author{
E. E. van der Wall
}

Published online: 6 July 2012

(C) The Author(s) 2012. This article is published with open access at Springerlink.com

The outcome of catheter ablation procedures for cardiac arrhythmias depends on the ability to evaluate the underlying mechanism and to depict target sites for ablation [1-10]. Image fusion and integration have become routine procedures in the diagnosis and treatment of various cardiovascular disorders [11-16]. Fusion of different imaging modalities within one system may improve electroanatomical modelling and facilitate ablation procedures. Nowadays, threedimensional (3D) navigation systems are widely used for pulmonary vein antrum isolation [17-24]. However, use of electroanatomical mapping systems may increase procedural duration and overheads, and may limit the choice of ablation catheters. As an alternative to circumvent left atrial mapping, 3D computed tomography (CT) reconstructions of the left atrium can be superimposed directly (CT overlay) on the fluoroscopy image to guide ablation catheters and to mark ablation sites.

In the present issue of the Netherlands Heart Journal, Van der Voort et al. [25] describe their initial experience with 3D overlay for ablation of atrial fibrillation. They evaluated the feasibility of the CT overlay technique for pulmonary vein antrum isolation and its equivalence to established electroanatomical mapping. To this purpose,

E. E. van der Wall

Interuniversity Cardiology Institute of the Netherlands

(ICIN)-Netherlands Heart Institute (NHI),

Utrecht, the Netherlands

e-mail: ernst.van.der.wall@icin.knaw.nl

E. E. van der Wall $(\bowtie)$

Department of Cardiology, Leiden University Medical Center,

Albinusdreef 2, Postal zone: K5-35, P.O. Box 9600,

2300 RC, Leiden, the Netherlands

e-mail: e.e.van_der_wall@lumc.nl the authors performed circumferential pulmonary vein ablation in 71 patients with atrial fibrillation. They performed $3 \mathrm{D}$ reconstructions of the left atrium, which were derived from contrast cardiac $\mathrm{CT}$ and circumferential pulmonary vein isolation. CT was initially performed using a 64-slice CT scanner, and later a 256-slice CT scanner, with $85 \mathrm{ml}$ of intravenous contrast. Initial follow-up was scheduled at 2 to 3 months after each ablation, at 6 months, and for every 6 months subsequently. In subsequent ablation procedures, veins were re-isolated, and defragmentation or linear lesions were performed if necessary. Outcome was based on symptoms and subsequent electrocardiographic confirmation of atrial fibrillation or tachycardia. The authors found that adequate $3 \mathrm{D}$ reconstructions were formed and registered to fluoroscopy in all patients. All veins, except 2 in one single patient, could be isolated, resulting in freedom of atrial fibrillation in 45 patients $(63 \%)$. In 19 patients a second procedure was performed, in which $2.7 \pm 1.1$ pulmonary veins per patient were re-isolated; in 3 patients a third procedure was performed. After follow-up of $15 \pm 8$ months, $51(91 \%)$ patients with paroxysmal and $10(67 \%)$ with persistent atrial fibrillation were free of arrhythmia.

The authors concluded that the results of 3D overlay for circumferential pulmonary vein isolation are good. The $3 \mathrm{D}$ overlay technique is comparable with other techniques, both for paroxysmal and persistent atrial fibrillation. In addition, it was demonstrated that the need for subsequent ablations remains high due to a high incidence of recovery of conduction from the pulmonary veins, but the recovery rate was similar to standard techniques. Therefore, the outcomes of the 3D overlay technique generally appear to be equivalent to other mapping techniques. The authors further claim that, based on other studies, their method of image integration is feasible in terms of handling radiation exposure and having lower costs. 
However, nowadays both patients and operators are entitled to know the exact radiation dose they receive. Therefore, precise data regarding the total radiation burden should be provided. Along those lines, the potential cost reduction associated with the $3 \mathrm{D}$ overlay technique should be given in more accurate terms, certainly when the $3 \mathrm{D}$ technique is said to be equivalent to other mapping techniques.

In a previous study by the same group [26], the authors had already successfully evaluated 68 patients with symptomatic atrial fibrillation refractory to medical therapy who were randomly assigned to CT overlay (group $1, n=38$ ) or to a new image integration module called CartoMerge (group $2, n=30$ ). In that study they found that CT overlay for pulmonary vein isolation is feasible and may, in comparison with conventional left atrial navigation systems, shorten procedural time without an increase in radiation burden.

In our centre, Tops et al. [27] had already shown in 16 patients with atrial fibrillation that CT images can be fused with the three-dimensional electroanatomical mapping system in an accurate manner. It was concluded that anatomybased catheter ablation procedures for atrial arrhythmias may be facilitated by integration of different imaging modalities. Also, Kardos et al. [28] showed that highly accurate CT imaging and the electroanatomical map fusion can be obtained by the Carto 3D electroanatomical mapping system using the coronary sinus as the key anatomical structure for registration. Using this technique the mapping time of the left atrium can be reduced. Finlay et al. [29], however, recently found in the CAVERN trial that CartoMerge appears to be faster and uses less fluoroscopy to achieve registration than 3D image integration using NavX Fusion, but overall procedural times and clinical outcomes were similar.

To summarise, although the current study provides promising data, a prospective, randomised study should be conducted-as the authors also indicated-to adequately compare the current CT overlay technique with standard electroanatomical mapping systems in patients eligible for ablation of atrial fibrillation.

Open Access This article is distributed under the terms of the Creative Commons Attribution License which permits any use, distribution, and reproduction in any medium, provided the original author(s) and the source are credited.

\section{References}

1. Heemstra HE, Nieuwlaat R, Meijboom M, et al. The burden of atrial fibrillation in the Netherlands. Neth Heart J. 2011;19:373-8.

2. Hendriks JL, Nieuwlaat R, Vrijhoef HJ, et al. Improving guideline adherence in the treatment of atrial fibrillation by implementing an integrated chronic care program. Neth Heart J. 2010;18:471-7.
3. Van Gelder IC, Smit MD, Alings M, et al. Upstream therapy in patients with early atrial fibrillation: the relevance of the routine versus aggressive upstream rhythm control for prevention of early atrial fibrillation in heart failure (RACE 3) study. Neth Heart J. 2010;18:522-3.

4. Dekker LR. Treatment of atrial fibrillation in the elderly: time for a change? Neth Heart J. 2011;19:403-4.

5. Underwood SR, Bax JJ, vom Dahl J, et al. Imaging techniques for the assessment of myocardial hibernation. Report of a Study Group of the European Society of Cardiology. Eur Heart J. 2004;25:81536.

6. van der Wall EE. New guidelines for the management of atrial fibrillation: what's new? Neth Heart J. 2010;18:519.

7. Hof IE, Wildbergh TX, van Driel VJ, et al. Atrial fibrillation with a giant left atrial appendage can be successfully treated with pulmonary vein antrum isolation. Neth Heart J. 2012;20:179-81.

8. Oude Velthuis B, Stevenhagen J, van Opstal JM, et al. Continuation of vitamin $\mathrm{K}$ antagonists as acceptable anticoagulation regimen in patients undergoing pulmonary vein isolation. Neth Heart J. 2012;20:12-5.

9. Tops LF, van der Wall EE, Schalij MJ, et al. Multi-modality imaging to assess left atrial size, anatomy and function. Heart. 2007;93:1461-70.

10. Van de Veire NR, Schuijf JD, De Sutter J, et al. Non-invasive visualization of the cardiac venous system in coronary artery disease patients using 64-slice computed tomography. J Am Coll Cardiol. 2006;48:1832-8.

11. Tops LF, Van de Veire NR, Schuijf JD, et al. Noninvasive evaluation of coronary sinus anatomy and its relation to the mitral valve annulus: implications for percutaneous mitral annuloplasty. Circulation. 2007;115:1426-32.

12. De Groot JR. A wider scope on the treatment of atrial fibrillation. Neth Heart J. 2012;20:143-5.

13. Henneman MM, Schuijf JD, Pundziute G, et al. Noninvasive evaluation with multislice computed tomography in suspected acute coronary syndrome: plaque morphology on multislice computed tomography versus coronary calcium score. J Am Coll Cardiol. 2008;52:216-22.

14. Groenink M, Lohuis TA, Tijssen JG, et al. Survival and complication free survival in Marfan's syndrome: implications of current guidelines. Heart. 1999;82:499-504.

15. Bleeker GB, Mollema SA, Holman ER, et al. Left ventricular resynchronization is mandatory for response to cardiac resynchronization therapy: analysis in patients with echocardiographic evidence of left ventricular dyssynchrony at baseline. Circulation. 2007;116:1440-8.

16. van der Wall EE, Heidendal GA, den Hollander W, et al. Metabolic myocardial imaging with 123I-labeled heptadecanoic acid in patients with angina pectoris. Eur J Nucl Med. 1981;6:391-6.

17. de Roos A, Doornbos J, van der Wall EE, et al. MR imaging of acute myocardial infarction: value of Gd-DTPA. AJR Am J Roentgenol. 1988;150:531-4.

18. van der Wall EE, Vliegen HW, de Roos A, et al. Magnetic resonance imaging in coronary artery disease. Circulation. 1995;92:2723-39.

19. Matheijssen NA, Louwerenburg HW, van Rugge FP, et al. Comparison of ultrafast dipyridamole magnetic resonance imaging with dipyridamole SestaMIBI SPECT for detection of perfusion abnormalities in patients with one-vessel coronary artery disease: assessment by quantitative model fitting. Magn Reson Med. 1996;35:221-8.

20. Kirschbaum SW, de Feyter PJ, van Geuns RJ. Cardiac magnetic resonance imaging in stable ischaemic heart disease. Neth Heart J. 2011;19:229-35.

21. Olimulder MA, Galjee MA, van Es J, et al. Contrast-enhancement cardiac magnetic resonance imaging beyond the scope of viability. Neth Heart J. 2011;19:236-45. 
22. Groothuis JG, Beek AM, Meijerink MR, et al. Towards a noninvasive anatomical and functional diagnostic work-up of patients with suspected coronary artery disease. Neth Heart J. 2010;18:270-3.

23. Lexis CP, Rahel BM, van Langen $\mathrm{H}$, et al. Cardiac magnetic resonance imaging in daily practice in a peripheral medical centre: description of the first 383 patients. Neth Heart J. 2010;18:524-30.

24. Jongbloed MR, Bax JJ, de Groot NM, et al. Radiofrequency catheter ablation of paroxysmal atrial fibrillation; guidance by intracardiac echocardiography and integration with other imaging techniques. Eur J Echocardiogr. 2003;4:54-8.

25. van der Voort PH, Stevenhagen J, Dekker LR, et al. Threedimensional computed tomography overlay for pulmonary vein antrum isolation: follow-up and clinical outcomes. Neth Heart J. 2012 Jun 1. doi:10.1007/s12471-012-0293-7
26. Stevenhagen J, Van Der Voort PH, Dekker LR, et al. Threedimensional CT overlay in comparison to CartoMerge for pulmonary vein antrum isolation. J Cardiovasc Electrophysiol. 2010;21:634-9.

27. Tops LF, Bax JJ, Zeppenfeld K, et al. Fusion of multislice computed tomography imaging with three-dimensional electroanatomic mapping to guide radiofrequency catheter ablation procedures. Hear Rhythm. 2005;2:1076-81.

28. Kardos A, Foldesi C, Ladunga K, et al. Pulmonary vein isolation without left atrial mapping. Indian Pacing Electrophysiol J. 2007;7:142-7.

29. Finlay MC, Hunter RJ, Baker V, et al. A randomised comparison of Cartomerge vs. NavX fusion in the catheter ablation of atrial fibrillation: the CAVERN Trial. J Interv Card Electrophysiol. 2012;33:161-9. 